\title{
Predição da Acidose no Nascimento em Gestações com Diástole Zero ou Reversaà Dopplervelocimetria das Artérias Umbilicais
}

\author{
Autor: Rossana Pulcinelli Vieira Francisco \\ Orientador: Prof. Dr. Seizo Miyadahira
}

Dissertação de Mestrado apresentada ao Departamento de Obstetrícia e Ginecologia da Faculdade de Medicina da Universidade de São Paulo - Disciplina de Obstetrícia em 14/4/99.

Resumo: Analisaram-se trinta gestações com diástole zero ou reversa à dopplervelocimetria das artérias umbilicais a fim de determinar a relação entre os testes de avaliação da vitalidade fetal e a presença de acidose no nascimento nestes casos. Para estudo do bem-estar fetal utilizaram-se cardiotocografia, perfil biofísico fetal, indice de líquido amniótico e dopplervelocimetria arterial (aorta torácica descendente e artéria cerebral média) e venosa (ducto venoso) fetal. A análise dos testes de avaliação da vitalidade fetal demonstrou que apenas o estudo do ducto venoso (análise do índice de pulsatilidade para veias e classificação segundo a curva de normalidade para a idade gestacional) relacionou-se de forma estatisticamente significativa com a acidose no nascimento. Estas duas variáveis foram selecionadas para o ajuste do modelo de regressão logística que apontou o índice de pulsatilidade para veias do ducto venoso como a variável capaz de predizer a probabilidade de acidose no nascimento. O conhecimento de um fator de predição para acidose no nascimento em gestações com diástole zero ou reversa pode facilitar a escolha do melhor momento para a interrupção da gestação. Demonstra-se a importância e a aplicabilidade do estudo do ducto venoso, nas gestações com fluxo diástolico ausente ou reverso nas artérias umbilicais.

Palavras-chave: Cardiotocografia. Dopplervelocimetria. Vitalidade fetal. Anóxia perinatal. \begin{tabular}{l|l}
$\mathrm{RBCO}$ & $22(1): 56,2000$
\end{tabular}

\section{Mamografia, Ultra-Sonografia e Ressonância Magnética na Avaliação da Ruptura de Próteses Mamárias de Silicone em Pacientes Assintomáticas: Achados com Correlação Cirúrgica}

Autor: Anabel Medeiros Scaranelo

Orientador: Prof. Dr. Henrique Manoel Lederman

Tese de Doutorado apresentada ao Departamento de Diagnóstico por Imagem, Escola Paulista de Medicina UNIFESP, em 26/4/99.

Resumo: Trabalho prospectivo avaliando 83 próteses em 44 pacientes sem sinais de ruptura que tiveram suas inclusões removidas cirurgicamente por estarem descontentes com o aspecto estético, para determinação da sensibilidade e especificidade de métodos de imagem: mamografia, ultra-sonografia e ressonância magnética, utilizando critérios diagnósticos pré-determinados para ruptura. Foram realizadas mamografia e ultra-sonografia de 83 próteses e ressonância magnética de 77 próteses. Os sinais radiológicos encontrados são discutidos e os falsos positivo e negativo são retrospectivamente avaliados para identificar quais foram as falhas diagnósticas, utilizando-se os achados operatórios como padrão ouro. A sensibilidade e a especificidade da mamografia foram de 20 e $89 \%$, respectivamente; da ultra-sonografia, de 30 e $81 \%$, respectivamente, e da ressonância magnética, de 64 e $77 \%$. Ressaltam-se as diferenças apresentadas pelos grupos: próteses incluídas por motivo estético e por motivo oncológico. Concluímos que a ressonância magnética é o método preferencial isolado a ser utilizado, e recomendações de condutas são feitas a partir dos dados obtidos.

Palavras-chave: Mama: doenças benignas. Próteses mamárias. Mamografia. Ultra-sonografia. Ressonância magnética. 